\title{
Polysomnografi ved utredning av søvnlidelser
}

\begin{abstract}
BAKGRUNN Søvnproblemer forekommer svært hyppig i befolkningen og mange pasienter vil ha behov for en fullstendig utredning med polysomnografi med eller uten påfølgende søvnlatenstest. Vi vil her beskrive disse metodene og indikasjonene for undersøkelsene.
\end{abstract}

KUNNSKAPSGRUNNLAG Artikkelen er basert på forfatternes egne litteraturarkiv, kliniske erfaring og Retningslinjer for metoder i klinisk nevrofysiologi.

RESULTATER Polysomnografi er en helnatts undersøkelse av søvnen og innebærer skåring av søvnstadier basert på EEG-aktivitet, øyebevegelser og muskelspenning. I tillegg registreres bl.a. respirasjonsrelaterte variabler. Polysomnografi etterfulgt av multippel søvnlatens-test (MSLT) brukes ved mistanke om narkolepsi og ufrivillig innsovning på dagtid. Ved mistanke om parasomni bør utredning omfatte polysomnografi, fortrinnsvis med videoregistrering. Mistenker man søvnapné hos voksne, kan respiratorisk polygrafi ofte være tilstrekkelig. Ved utredning av søvnlidelser hos barn er polysomnografi som regel å foretrekke fremfor respiratorisk polygrafi.

FORTOLKNING Søvnlidelser gir seg mange utslag og håndteres av mange ulike spesialiteter. Et godt samarbeid mellom de ulike spesialitetene er nødvendig for et godt resultat for pasientene.

Norske undersøkelser viser at ca. $11-12 \%$ av den voksne befolkningen angir å ha søvnproblemer $(1,2)$. Søvnlidelser kan gi betydelig forringet livskvalitet, i tillegg til at flere av dem er forbundet med annen helserisiko. Det er etablert gode behandlingstilbud for de fleste søvnsykdommene, og det er derfor viktig at pasientene har tilgang til diagnostisk utredning.

Søvnforstyrrelser kan grovt deles inn i manglende søvn (insomni), uønsket søvn om dagen (hypersomni/narkolepsi) eller forstyrret søvn (søvnapné, rastløse bein, uønsket atferd som søvngjengeri etc.). Anamnese, inkludert søvndagbok, og eventuelt spørreskjema om symptomer og sovevaner, samt generell undersøkelse er grunnleggende for videre utredning av de fleste søvnsykdommer. Ved vanlig insomni er søvndagbok og klinisk undersøkelse oftest tilstrekkelig for å stille diagnosen. Ved andre og sammensatte problemstillinger er det behov for en undersøkelse som kan gi et objektivt bilde av søvnen. Polysomnografi (PSG) med registrering av søvnkvalitet og respirasjonsvariabler under søvn brukes først og fremst under utredning, men kan også brukes ved mistenkt sviktende behandlingsrespons. Hensikten med denne artikkelen er å gi en oversikt over bruken av fysiologisk søvndiagnostikk med hovedvekt på polysomnografi. Polysomnografi innebærer registrering med elektroencefalografi (EEG) og flere, særlig respirasjonsrelaterte, variabler under vanlig nattesøvn. Artikkelen er basert på forfatternes egne litteraturarkiv, kliniske erfaring og kapittel 11 i Retningslinjer for metoder i klinisk nevrofysiologi del 1 (3).

\section{Hva er polysomnografi?}

Polysomnografi er en helnatts undersøkelse av søvnen og er indisert ved en rekke søvnrelaterte problemstillinger (4). En polysomnografi er ressurs- og tidkrevende, og pasienten er tilkoblet avansert registreringsutstyr i mange timer (se illustrasjon). Undersøkelsen omfatter skåring av søvnstadiene på bakgrunn av EEG-aktivitet, øyebevegelser (elektrookulografi, EOG) og muskelspenning (elektromyografi, EMG). I tillegg registreres respirasjonsrelaterte variabler som lyder, pustebevegelser over thorax og abdomen, oksygenmetning og elektrokardiografi (EKG). Dessuten registreres gjerne liggestilling og beinbevegelser (se illustrasjon). Avhengig av problemstillingen kan også andre målinger knyttes til registreringen, for eksempel trykkmålinger i oesophagus eller samtidig videofilming.

Pasienten møter ved utførende avdeling om ettermiddagen for å få påmontert utstyret. I Norge utføres polysomnografi oftest ambulatorisk og pasienten reiser hjem, legger seg og står opp til vanlig tid før utstyret kobles fra og leveres til tolking. Noen laboratorier foretar registreringen med pasienten sovende $\mathrm{i}$ avdelingen, der man lettere kan unngå forstyrrelser som f.eks. at elektroder løsner. Ved utredning av søvnrelaterte atferdsendringer (parasomnier) eller anfall sover pasienten med videoovervåking i utførende avdeling.

Feilkildene er mange: støy fra omgivelsene (inkludert elektromagnetisk påvirkning og registreringselektronikk i tillegg til luftstrøm gjennom nese og munn, snorkefra elektriske apparater), ustabile elektroder

\section{Morten Engstrøm}

morten.engstrom@ntnu.no

Institutt for nevromedisin

Det medisinske fakultet

Norges teknisk-naturvitenskapelige universitet og

Avdeling for nevrologi og klinisk nevrofysiologi St. Olavs hospital

\section{Eyvind Rugland}

Nevroklinikken

Seksjon for klinisk nevrofysiologi

Akershus universitetssykehus

Mona Skard Heier

Toppen 12

1169 Oslo

\section{HOVEDBUDSKAP}

Søvnlidelser forekommer hyppig, og rett diagnose må stilles før eventuell behandling

Polysomnografi er en undersøkelse av søvnmengde og søvnkvalitet og er nødvendig for å utrede mange søvnlidelser med hypersomni på dagtid, anfall, adferdsendring eller unormal motorisk aktivitet nattestid

Ved mistanke om søvnapné hos voksne kan respiratorisk polygrafi være tilstrekkelig

Polysomnografi foretrekkes ofte fremfor respiratorisk polygrafi i søvnutredning av barn 

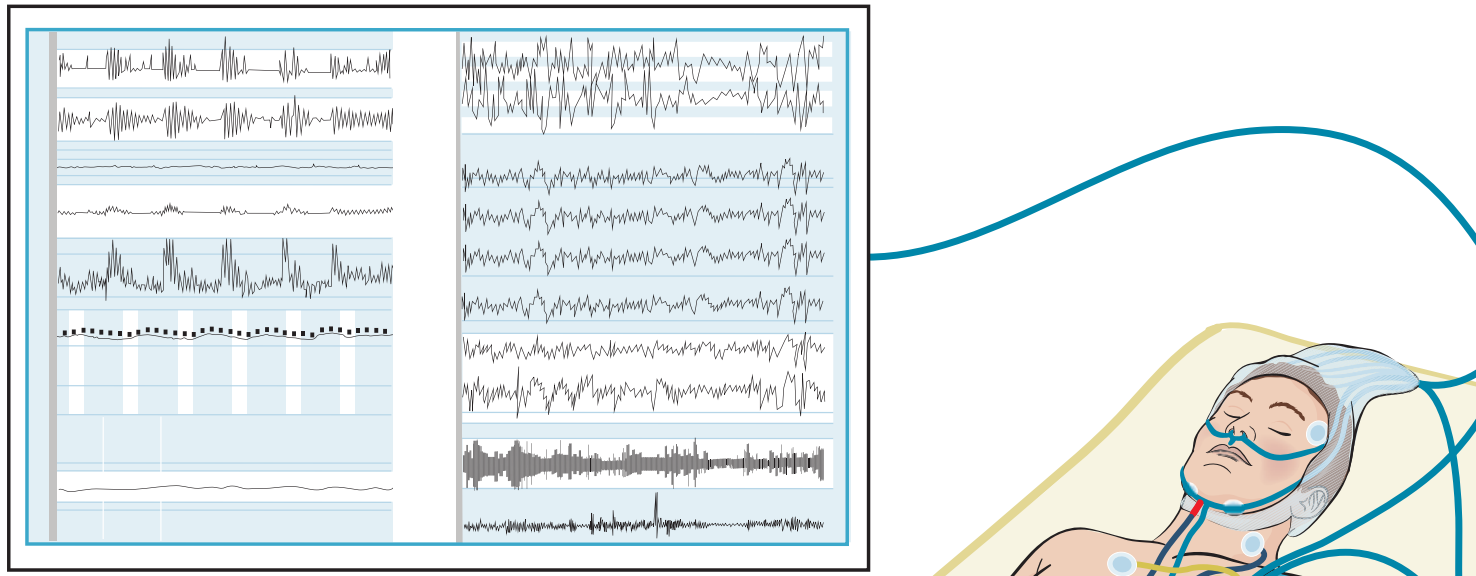
Tabell 1 Indikasjoner for søvnregistrering

$\begin{array}{ll}\text { Indikasjon } & \text { Type registrering } \\ \text { Mistanke om hypersomni/narkolepsi } & \begin{array}{l}\text { Polysomnografi med etterfølgende } \\ \text { multippel søvnlatens-test }\end{array} \\ \text { Mistanke om søvnrelatert respirasjonsforstyrrelse } & \begin{array}{l}\text { Hos voksne: respiratorisk polygrafi } \\ \text { oftest tilstrekkelig } \\ \text { Hos barn: polysomnografi }\end{array}\end{array}$

Mistanke om søvnrelatert respirasjonsforstyrrelse eller periodiske beinbevegelser under søvn som årsak

til insomni.

Ved uttalte insomnisymptomer med mistanke om

paradoks insomni og behov for dokumentasjon

Uvanlig voldelig eller skadelig atferd under $\varsigma \varnothing v n$ (parasomni)

Polysomnografi med videoregistrering

Kontrollregistrering ved mistenkt sviktende behand-

lingsrespons

Avhengig av tilstand, se over bevegelser hos pasienten. Tolkingsarbeidet for de mange registrerte variablene i 7-8 timer med søvn er ofte tidkrevende. Det er utarbeidet flere automatiske søvnskåringseller tolkingsprogrammer, men anbefaling (5) og erfaring tilsier at skåringen bør kontrolleres $a v$ en person med erfaring $i$ søvnskåring på grunn av faren for artefakter og feiltolking.

\section{Bedømming av søvnvariabler}

Ved tolking av en søvnregistrering vil man bedømme søvnens mengde og kvalitet. Grunnlaget for dette er målinger av innsovningstiden, total søvntid, antall og varighet av oppvåkninger i løpet av søvnperioden og mengde og fordeling av de ulike søvnstadiene.

Normal søvn veksler mellom to hovedkomponenter, REM-søvn og ikke-REMsøvn (NREM-søvn) (se illustrasjon). Søvn med raske øyebevegelser kalles REM (Rapid Eye Movement)-søvn og inneholder de mest livaktige drømmene. REM-søvn dominerer tidlig i fosterlivet og reduseres gradvis til omkring tiårsalder hvor andelen er på voksent nivå, det vil si omkring $20 \%$ av søvnen (6). I EEG ses ved REM-søvn relativt lavamplitudig og rask aktivitet forenlig med lett søvn og er ledsaget av hypotoni i postural muskulatur og raske øyebevegelser. NREM-søvnen deles inn i stadier bl.a. etter økende mengde synkron langsom aktivitet og økende amplitude som uttrykk for økende søvndybde. Den fysiologiske betydningen av de to søvnfasene er fortsatt omdiskutert, men REM-søvn er ofte oppfattet å ha betydning for læring, mens NREM i større grad har betydning for hvile og restitusjon (6). Etter innsovning blir søvnen vanligvis gradvis dypere før det kommer en periode med REM-søvn. Vekslingen mellom NREM og REM gjentar seg vanligvis 4-6 ganger i løpet av natten i en ca. 90 minutters syklus, der det gradvis blir mindre dyp søvn og gradvis mer REM-søvn.

\section{Bedømming av respirasjon under søvn}

Hos voksne telles episoder med respirasjonsstopp (apné) eller betydelig redusert respirasjon (hypopné) som varer mer enn ti sekunder. Antall apneer og hypopneer per time søvn angis ved en apné-hypopné-indeks (AHI). Det er ikke full enighet i fagmiljøene om hva som er den beste måten å definere episodene på. Den nordamerikanske søvnforeningen (American Academy of Sleep Medicine, AASM) anbefaler i sin skåringsmanual at apneer måles med termistor (registrerer temperaturendringer foran nese og munn og derigjennom luftstrøm i ekspirasjon og inspirasjon), mens hypopneer måles best med en nasal trykkmåler (7). Hos voksne telles episoder med apné og hypopné som varer mer enn ti sekunder. Hvis apneen er ledsaget av respiratoriske bevegelser over thorax og abdomen, karakteriseres den som obstruktiv, og ved manglende respiratoriske bevegelser som sentral (i betydningen sentralnervøs). Hos voksne er obstruktiv søvnapné definert ved apné-hypopné-indeks $\geq 15$ alene eller $\geq 5$ ved tilleggssymptomer som dagtretthet, insomni, slitenhet, snorking og gisping etter luft under søvn (8). Apné-hypopné-indeks 5-15 ledsaget av symptomer er definert som lettgradig søvnapné, 15-30 som moderat og $>30$ som uttalt (9).

Hos barn telles episoder som er lenger enn to respiratoriske sykler. Øvre normalgrense hos barn er angitt å være apné-hypopnéindeks $=1(8)$, men gode normalmaterialer mangler. Det er anbefalt å bruke voksne verdier fra 13-årsalder (7), og overgangen mellom barne- og voksengrensene må bli skjønnsmessig.

\section{Multippel søvnlatens-test}

Multippel søvnlatens-test (MSLT) er en søvnregistrering som brukes til å kartlegge søvnighet på dagtid og er en viktig undersøkelse ved sentralnervøse hypersomnier (10). Undersøkelsen foregår om dagen etter en polysomno- grafi foregående natt, slik at man kan utelukke andre årsaker til dagtretthet, som f.eks. lite søvn, urolig søvn eller søvnapnésyndrom. Det gjøres 4-5 innsovningstester med to timers intervaller, hver med varighet minimum 20 minutter, med registrering av de nødvendige variablene for å bestemme søvnstadiene (EEG, øyebevegelser og muskelspenning). Man måler gjennomsnittlig innsovningstid (søvnlatens) og latenstid til REM-søvn, som vanligvis først opptrer etter 70 minutter søvn (6). REM-søvn kan opptre tidligere, for eksempel ved obstruktiv søvnapné (11). Opptreden av REM-søvn mindre enn 15 min etter innsovning kalles «sleep onset REM» eller SOREM.

\section{Utredning med polysomnografi}

Tabell 1 gir en kortfattet oversikt over indikasjoner og registreringsmetoder.

\section{Insomni}

Insomni er en klinisk diagnose og polysomnografi er i de aller fleste tilfeller ikke nødvendig. Ved mistanke om spesifikke årsaker til insomni (obstruktiv søvnapné eller periodiske beinbevegelser) og hos middelaldrende kvinner samt eldre som oftere har slike tilleggsdiagnoser (12), kan polysomnografi ha diagnostisk nytte. For dem som føler at de ikke sover i det hele tatt, kan polysomnografi være nyttig for å få vite at de likevel sover en hel del.

\section{Døgnrytmeforstyrrelser}

Ved døgnrytmeforstyrrelser er søvnen oftest normal, men forsinket $\mathrm{i}$ forhold til vanlig rytme. Polysomnografi er oftest ikke indisert, men normalt god søvn kan eventuelt dokumenteres dersom det er tvil om dette. Rytmeforstyrrelsen dokumenteres med søvndagbok som noen ganger verifiseres med en bevegelsesmåler på håndleddet (aktigrafi).

\section{Søvnrelaterte respirasjonslidelser}

Ut fra befolkningsstudier anslår man en forekomst av obstruktiv søvnapné på ca. 3-7\% hos menn og $2-5 \%$ hos kvinner i den voksne befolkningen (13). I tillegg til å forstyrre søvnen gir tilstanden tretthet på dagtid og fare for søvnanfall om dagen med særlig risiko i trafikksituasjoner og enkelte arbeidssituasjoner. Tilstanden kan også ha alvorlig innvirkning på helsen med økt risiko for hypertensjon, koronararteriesykdom, arytmi, hjertesvikt og slag (14). Pasienter med mistenkt obstruktiv søvnapné bør derfor utredes og eventuelt behandles.

Snorking og dagtretthet er vanlige årsaker til utredning. Hos voksne kan det særlig hos overvektige snorkere med forhøyet blodtrykk og hjerteproblemer m.m. være gode grunner til vurdering for søvnapné selv om pasienten ikke erkjenner plagsom dagtretthet.

Også barn kan ha obstruktiv søvnapné, med en prevalens på ca. $3-7 \%(5,15)$. Siden store tonsiller er den vanligste årsaken til obstruktiv søvnapné hos barn, er forekomsten 
høyest i aldersgruppen 4-6 år (5). For barn som puster tungt eller snorker under søvn kan dagtretthet, oppmerksomhetssvikt, lærevansker, mistrivsel, dårlig vekst og overvekt være tilleggsgrunner til å gjennomføre registrering av respirasjon under søvn.

Utredning av søvnapné hos voksne kan som hovedregel gjøres med respiratorisk polygrafi - en forenklet registrering av respirasjon - og liggestilling uten EEG. Fordelen er enklere utstyr og raskere tolking. Ulempen er først og fremst underestimering av de respiratoriske episodene ved at den faktiske søvntiden er kortere enn registreringstiden, og manglende mulighet til differensialdiagnostikk. Hos barn foretrekkes derfor ofte en registrering med EEG.

\section{Narkolepsi og idiopatisk}

sentralnervøs hypersomni

Ca. 2000 voksne nordmenn har narkolepsi med katapleksi (16), hvorav en betydelig andel antas fortsatt å være udiagnostisert. I tillegg er det et ukjent antall pasienter med narkolepsi uten katapleksi og idiopatisk sentralnervøs hypersomni. Dagsøvnighet er den vanligste problemstillingen ved disse tilstandene. Det er utarbeidet diagnostiske kriterier for narkolepsi og sentralnervøs hypersomni, der spesifikke funn ved polysomnografi og multippel søvnlatens-test inngår (8). Ved mistanke om narkolepsi eller sentralnervøs hypersomni er polysomnografi med etterfølgende multippel søvnlatens-test derfor indisert. Det er anbefalt at polysomnografi gjennomføres natten før multippel søvnlatens-test (8) for å dokumentere en alminnelig god natts søvn og også for å utelukke andre tilstander som også kan medføre dagtretthet og kort søvnlatens (f.eks. søvnapné eller insomni). For å stille diagnosen narkolepsi eller idiopatisk sentralnervøs hypersomni kreves en gjennomsnittlig søvnlatenstid ved multippel søvnlatens-test på mindre enn åtte minutter. I tillegg inngår påvisning av to perioder med SOREM ved multippel søvnlatens-test $\mathrm{i}$ de diagnostiske kriteriene for narkolepsi (8). Både kort søvnlatens og SOREM kan iblant også ses ved søvnapnésyndrom og tilstander med uttalt søvndeprivasjon. Spesifisitet og sensitivitet for multippel søvnlatens-test ved diagnostikk av narkolepsi er ca. $70 \%$ (11). Enkelte ganger finner man bare SOREM ved én innsovningstest ved mistanke om narkolepsi. Hvis mistanken er sterk, anbefales det å gjenta undersøkelsen $(3,10)$.

Ca. $30-50 \%$ av pasienter med narkoleps får sine første symptomer som barn eller under puberteten (17). For å sikre best mulige forhold for skolegang og sosial tilpasning er det viktig at disse får tidlig diagnose og behandling. Det finnes ikke egne diagnostiske kriterier for multippel søvnlatens-test ved narkolepsi hos barn i ulike aldersgrupper, og man benytter vanligvis de samme kriteriene som for voksne $(17,18)$. Det kan by på særskilte problemer, spesielt ved diagnostikk av barn under skolealder, hvor samarbeidsevnen ved multippel søvnlatens-test kan være mangelfull. Måling av hypokretinmengde i spinalvæsken anses derfor i dag som et viktig diagnostisk supplement (19).

\section{Parasomnier}

Parasomnier er definert som uønskede fysiske hendelser eller erfaringer som forekommer ved innsovning, under søvn, eller under perioder med ufullstendig oppvåkning i løpet av søvnperioden (8)

Periodiske benbevegelser under søvn (periodic limb movements, PLM) kan forårsake tallrike kortvarige oppvåkninger eller nesten-oppvåkninger, slik at andelen dyp søvn reduseres. Tilstanden kan derfor være årsak til tretthet på dagtid og kan behandles (L-dopa/dopaminagonister) (20). Pasienten merker oftest ikke bevegelsene, men partner kan gjerne beskrive periodevis kraftig motorisk uro. Mange med periodiske beinbevegelser har også urolige bein ved innsovning, som er en klinisk diagnose (rastløse bein), mens periodiske beinbevegelser oftest må bekreftes ved en polysomnografi. Blant voksne insomnipasienter er det vist at periodiske beinbevegelser kan foreligge relativt ofte uten at det foreligger klinisk mistanke om rastløse bein eller periodiske beinbevegelser (12).

Ved REM-relatert atferdslidelse (REM sleep behaviour disorder, RBD) bestemmer drømmen den motoriske atferden fordi normal muskelatoni i REM-fasen er fraværende. Tilstanden kan medføre betydelig og til dels voldsom motorisk aktivitet under søvn, med risiko for skade på både pasient og de nærmeste. Siden man i dag har effektiv medikamentell behandling for dette (klonazepam, melatonin) (21), er det viktig med sikker diagnose. For å diagnostisere lidelsen bør polysomnografiregistreringen skje under videoovervåkning. Den motoriske aktiviteten skal da komme i REM-fasen. Dessuten kan manglende atoni i REM-fasen mer generelt påvises.

Differensialdiagnosene kan være nattlige epileptiske anfall, men pseudo-REM-relatertliknende atferdslidelse kan også forekomme ved obstruktiv søvnapné, nattlig skrekkanfall og søvngjengeri. Søvngjengeri er oppfattet å skyldes en ufullstendig oppvåkning ved aktivering fra dyp søvn. Tilstanden er vanligvis ikke en behandlingstrengende tilstand, men polysomnografi kan brukes for å utelukke differensialdiagnoser.

\section{Avslutning}

Norge har et stort og dels udekket behov for utredning med polysomnografi $(5,22)$. Opplæring i undersøkelsen inngår i spesialistutdanning for kliniske nevrofysiologer. De klinisk nevrofysiologiske seksjonene og avdelingene er derfor sentrale for polysomnografiutredningen, selv om undersøkelsen også utføres av andre spesialister som har fått tilstrekkelig god opplæring og erfaring. Behandling utføres av allmennleger (insomni), nevrologer (parasomni, narkolepsi, døgnrytmeforstyrrelser, nevrologisk komorbiditet), pediatere (alle søvnlidelser hos barn), lungeleger (CPAP/BIPAP, respirator), øre-nese-hals-leger (CPAP, operative behandlinger), tannleger (tilpasning av bittskinne), psykiatere og psykologer (alvorlig insomni, døgnrytmeforstyrrelser, psykiatrisk komorbiditet). Inntil det blir mer vanlig med organiserte søvnsentre der tilbudet er mer helhetlig, er det fornuftig å bruke ressurser på knytte sammen de ulike lokale aktørene. Et oversiktlig og minst mulig fragmentarisk tilbud vil være en klar fordel både for pasienten og for samfunnet.

\section{Morten Engstrøm (f. 1967)}

er spesialist i klinisk nevrofysiologi, ph.d.-stipendiat og overlege.

Forfatter har fylt ut ICMJE-skjemaet og oppgir følgende interessekonflikter: Han har bidratt med pasientinklusjon i en multisenterstudie rundt legemidler for insomni (Organon).

\section{Eyvind Rugland (f. 1963)}

er spesialist i klinisk nevrofysiologi og pediatri og seksjonsoverlege.

Forfatter har fylt ut ICMJE-skjemaet og har ingen oppgitte interessekonflikter.

\section{Mona Skard Heier (f. 1939)}

er dr.med, spesialist i nevrologi og i klinisk nevrofysiologi og akkreditert spesialist i søvnmedisin ved Nordisk forening for søvnforskning og søvnmedisin.

Forfatter har fylt ut ICMJE-skjemaet og har ingen oppgitte interessekonflikter.

\section{Litteratur}

1. Sivertsen B, Nordhus IH, Bjorvatn B et al. Sleep problems in general practice: a national survey of assessment and treatment routines of general practitioners in Norway. J Sleep Res 2010; 19 : 36-41.

2. Pallesen $\mathrm{S}$, Nordhus IH, Nielsen GH et al. Prevalence of insomnia in the adult Norwegian population. Sleep 2001; 24: 771-9

3. Sand T. red. Retningslinjer for metoder i klinisk nevrofysiologi del 1.2 utg. Oslo: Den norske legeforeningen, 2008: 221-44.

4. Kushida CA, Littner MR, Morgenthaler T et al. Practice parameters for the indications for polysomnography and related procedures: an update for 2005. Sleep 2005: 28: 499-521.

5. Skatvedt O, Riis S, Bjorvatn B et al. Utredning og behandling av søvnrelatert respirasjonsbesvær hos barn og voksne. Skriftserie for leger: Utdanning og kvalitetsutvikling 2002. Oslo: Den norske legeforening, 2002

6. McCarley RW. Neurobiology of REM and NREM sleep. Sleep Med 2007; 8: 302-30.

7. American Academy of Sleep Medicine. The AASM manual for the scoring of sleep and associated events. Rules, terminology and technical specifications. Westchester, IL: American Academy of Sleep Medicine, 2007

8. Sateia MJ. The international classification of sleep disorders. Diagnostic and coding manual. 2. utg. Westchester, IL: American Academy of Sleep Medicine, 2005

9. Epstein LJ, Kristo D, Strollo PJ Jr et al. Clinical guideline for the evaluation, management and long-term care of obstructive sleep apnea in adults. J Clin Sleep Med 2009; 5: 263-76. 
10. Littner MR, Kushida C, Wise M et al. Practice parameters for clinical use of the multiple sleep latency test and the maintenance of wakefulness test. Sleep 2005; 28: 113-21.

11. Aldrich MS, Chervin RD, Malow BA. Value of the multiple sleep latency test (MSLT) for the diagnosis of narcolepsy. Sleep 1997; 20: 620-9.

12. Crönlein T, Geisler P, Langguth B et al. Polysomnography reveals unexpectedly high rates of organic sleep disorders in patients with prediagnosed primary insomnia. Sleep Breath 2011; e-publisert 25.10.2011.

13. Lurie A. Obstructive sleep apnea in adults: epidemiology, clinical presentation, and treatment options. Adv Cardiol 2011; 46: 1-42.

14. Devulapally K, Pongonis R Jr, Khayat R. OSA: the new cardiovascular disease: part II: Overview of cardiovascular diseases associated with obstructive sleep apnea. Heart Fail Rev 2009; 14: 155-64.

15. Gislason T, Benediktsdóttir B. Snoring, apneic episodes, and nocturnal hypoxemia among children 6 months to 6 years old. An epidemiologic study of lower limit of prevalence. Chest 1995; 107: 963-6.

16. Heier MS, Evsiukova T, Wilson J et al. Prevalence of narcolepsy with cataplexy in Norway. Acta Neurol Scand 2009; 120: 276-80.

17. Challamel MJ, Mazzola ME, Nevsimalova S et al. Narcolepsy in children. Sleep 1994; 17 (suppl): S17-20.

18. Heier MS. Narkolepsi hos barn-en diagnostisk og terapeutisk utfordring. Tidsskr Nor Lægeforen 1998; 118: 2961-3.

19. Heier MS, Evsiukova T, Vilming $S$ et al. CSF hypocretin-1 levels and clinical profiles in narcolepsy and idiopathic CNS hypersomnia in Norway. Sleep 2007; 30: 969-73.

20. Natarajan R. Review of periodic limb movement and restless leg syndrome. J Postgrad Med 2010; 56: 157-62.

21. Boeve BF, Silber MH, Ferman TJ. Melatonin for treatment of REM sleep behavior disorder in neurologic disorders: results in 14 patients. Sleep Med 2003; 4: $281-4$.

22. Sand T. Søvnlidelser må utredes før behandling. Tidsskr Nor Lægeforen 2004; 124: 2877.

Mottatt 8.2. 2012, første revisjon innsendt 2.5. 2012, godkjent 21.6. 2012. Medisinsk redaktør Siri Lunde. 